\title{
Pengendalian hama padi secara terpadu di Desa Pulau Rambai Kabupaten Kampar
}

\author{
Hafiz Fauzana $^{1 \star}$, Rusli Rustam ${ }^{1}$, Nelvia $^{1}$, Susilawati ${ }^{2}$, Husnayetti ${ }^{1}$, \\ Irfandri ${ }^{1}$, dan Wardati ${ }^{1}$ \\ ${ }^{1}$ Fakultas Pertanian, Universitas Riau \\ ${ }^{2}$ Fakultas Keguruan dan IImu Pendidikan, Universitas Riau \\ *fauzana_hafiz@yahoo.co.id
}

\begin{abstract}
Rice commodities are the main food and are widely planted in Pulau Rambai Village, Kampa District, Kampar Regency. Pest attacks are the main obstacle in cultivating rice. The concept of integrated pest management (PHT) is applied to rice farmers. This management includes combining compatible pest management techniques, prioritizing natural management using natural enemies. This activity aims to provide counselling, assistance and guidance to rice farmers to implement PHT to increase the quantity and quality of rice production. The intended target was rice farmers in Pulau Rambai Village. The method of implementation carried out is counselling, mentoring and assisting. Counselling is in the form of presentation on farmers' paddy farms introducing the concept of PHT, management of plant cultivation that is not suitable for rice pest development, the introduction of natural enemies of pests, and types of environmentally friendly control such as vegetable pesticides and biological agents. Guidance and mentoring were also given to farmers in monitoring pests, natural enemies, and rice ecosystems. The level of achievement of the program targets was monitored from the questionnaire filled out by farmers before counselling and at the end of the mentoring activities program. From the questionnaire, there was a change in the views and knowledge of farmers in the concept of pest control. The program's achievement is also seen from the change in cultivation methods such as the legowo $4 \times 1$ system with three seeds per clump and pest control using biological pesticides according to the guidance.
\end{abstract}

\begin{abstract}
Abstrak Komoditas padi merupakan pangan utama dan banyak ditanam di Desa Pulau Rambai Kecamatan Kampa Kabupaten Kampar. Serangan hama merupakan kendala utama dalam pembudidayaan tanaman padi. Konsep Pengendalian Hama Terpadu (PHT) diterapkan ke petani padi yaitu memadukan teknik pengendalian hama yang kompatibel, mengutamakan pengendalian alami menggunakan musuh alami. Pengabdian bertujuan memberikan penyuluhan, pendampingan dan bimbingan petani padi menerapkan PHT untuk meningkatkan kuantitas dan kualitas produksi padi. Sasaran yang ditujukan adalah petani padi di Desa Pulau Rambai. Metoda penerapan yang dilakukan adalah penyuluhan, pembimbingan dan pendampingan. Penyuluhan berupa penyajian di pondok sawah petani mengenalkan konsep PHT, pengelolaan budidaya tanaman yang kurang sesuai untuk perkembangan hama padi, dan pengenalan jenis musuh alami hama, dan jenis pengendalian yang ramah lingkungan seperti pestisida nabati dan agen hayati. Pembimbingan dan pendampingan petani dalam pemantauan hama, musuh alami, dan ekosistem padi. Tingkat ketercapaian sasaran program terpantau dari kuisioner yang diisi oleh petani sebelum penyuluhan dan akhir program kegiatan pendampingan. Dari kuisioner terlihat adanya perubahan
\end{abstract}

\section{○ OPEN ACCESS}

Citation: Fauzana, H., R. Rustam, Nelvia, Susilawati, Husnayetti, Irfandri, \& Wardati. 2019. Pengendalian hama padi secara terpadu di Desa Pulau Rambai Kabupaten Kampar. Riau Journal of Empowerment 2(1): 27-35 https://doi.org/10.31258/raje.2.1.21

Received: 2019-02-11, Revised: 2019-05-16, Accepted: 2019-05-29

Funding: Terima kasih kepada Lembaga Penelitian dan Pengabdian kepada Masyarakat Universitas Riau skema Desa Binaan tahun 2018 dibawah DIPA Universitas Riau dengan nomor kontrak 1353/UN.19.5.1.3/PP/2018 yang telah memberikan dana untuk pelaksanaan kegiatan desa binaan di Desa Pulau Rambai Kecamatan Kampa Kabupaten Kampar

Language: Bahasa Indonesia (id)

(C) 2019 Hafiz Fauzana et al. The article by Author(s) is licensed under a Creative Commons Attribution 4.0 International License. This license permits unrestricted use, distribution, and reproduction in any medium, provided the original author and source are credited. 
pandangan dan pengetahuan petani dalam konsep pengendalian hama. Ketercapaian program juga terlihat dari adanya perubahan cara budidaya seperti sistem legowo $4 \mathrm{x} 1$ dengan 3 bibit per rumpun dan pengendalian hama menggunakan pestisida hayati sesuai yang disuluhkan.

Keywords: integrated pest management; rice pest; monitoring; natural enemies; biological pesticides

\section{PENDAHULUAN}

Tanaman padi merupakan komoditi pangan utama lebih dari $70 \%$ penduduk Indonesia. Kebutuhan pangan terus meningkat setiap tahunnya, peningkatan produksi pangan tidak sebanding dengan laju pertambahan penduduk. Kabupaten Kampar salah satu penghasil padi di Riau. Luas panen sawah di Kabupaten Kampar tahun 2013 mencapai 10.088 ha dengan produksi sebesar 48.020,34 ton. Kecamatan Kampa Kabupaten Kampar salah satu wilayah penghasil padi mempunyai lahan sawah seluas 693 ha, panen padi sawah 1.116 ton dengan produksi 5.301 ton dengan rata-rata produksi masih sangat rendah yaitu 4,92 ton/ha (BPS Kabupaten Kampar, 2018).

Desa Pulau Rambai salah satu desa penghasil padi produktif di Kecamatan Kampa Kabupaten Kampar. Komoditas padi ketiga paling banyak dibudidayakan petani setelah karet dan kelapa sawit. Luas lahan padi di Desa Pulau Rambai mencapai 286 ha atau 5,18\%. Jumlah penduduk di Desa Pulau Rambai sebanyak 3542 orang dengan 823 kepala keluarga. Pekerjaan masyarakatnya adalah bertani sebanyak 629 orang $(17,78 \%)$.

Kegiatan ekonomi desa Pulau Rambai didominasi oleh sektor pertanian dan perkebunan. Penanaman padi dilakukan 1 kali tanam per tahun secara serentak, penanaman sekitar bulan Mei sampai September. Produksi padi di Desa Pulau Rambai belum maksimal akibat sering terkendala oleh serangan hama. Pengendalian hama pada budidaya padi masihbertumpu pada penggunaan pestisida sintetik, sedangkan dalam konsep pengendalian hama pada tanaman padi yang direkomendasikan adalah pengendalian hama terpadu (PHT).

Konsep PHT berkembang dan diterapkan dilandasi prinsip yaitu pemahaman ekosistem pertanian, biaya manfaat pengendalian hama, toleransi tanaman terhadap kerusakan, populasi hama yang dipertahankan agar musuh alami dapat berkembang dalam menjalankan fungsinya sebagai pengendali di ekosistem pertanian, pemanfaatan dan pelestarian musuh alami, budidaya tanaman yang sehat, pemantauan ekosistem (hama, musuh alami, tanaman dan komponen ekosistem lainnya), pemberdayaan petani dan pemasyarakatan konsep PHT. Unsur dasar PHT adalah pengendalian alami, pengambilan sampel (pemantauan rutin), aras ekonomi pengendalian hama, dan pemahaman ekologi dan biologi hama (Untung, 2006).

Pengendalian hama terpadu yang diterapkan dalam pengelolaan tanaman padi belum begitu diketahui dan diterapkan petani padi di Desa Pulau Rambai, sehingga sangat diperlukan penyuluhan pengendalian hama terpadu pada budidaya padi agar serangan hama dapat diatasi dan produksi padi lebih aman dari residu pestisida sintetik. Aplikasi pestisida mempengaruhi keanekaragaman serangga (Wanger et al., 2010) termasuk musuh alami dan serangga berguna lain seperti polinator (Brittain et al., 2010), serta memicu terjadinya resistensi hama seperti wereng coklat (Matsumura and Sanada-Morimura, 2010). Berpatokan dari itu penyuluhan dan pendampingan penerapan pengendalian hama terpadu adalah sangat penting untuk membudayakan petani mengelola serangan hama secara alami, aman, dengan mengurangi penggunaan pestisida dan menerapkan konsep pertanian berkelanjutan.

\section{Perumusan Masalah}

Tanaman padi merupakan salah satu komoditi andalan di Desa Pulau Rambai Kecamatan Kampa Kabupaten Kampar. Pekerjaan penduduk terutamabertani padi, disamping karet dan kelapa sawit. Serangan hama pada tanaman padi cukup tinggi terutama hama tikus, keong mas, wereng coklat, dan walang sangit. Pengendalian utama yang dilakukan petani menggunakan insektisida sintetik. Pengendalian hama yang dianjurkan untuk hama padi adalah PHT, konsep PHT ini belum diterapkan petani dalam mengendalikan hama padi, sedangkan konsep PHT 
timbul awalnya dari permasalahan hama pada tanaman padi. Oleh karenanya penerapan pengendalian hama terpadu perlu dikenalkan, dimasyarakatkan dan dikembangkan ke petani.

Fauzana dkk.

Solusi permasalahan penerapan PHT adalah dengan melakukan penyuluhan yaitu cara teknik budidaya yang sehat yang tidak memicu serangan hama dan mendukung pelestarian musuh alami, pengenalan pengendalian yang aman, ramah lingkungan yaitu penggunaan bahan alam seperti pestisida nabati dan hayati. Solusi selanjutnya adalah melakukan pendampingan dan bimbingan petani, melakukan pengamatan atau monitoring hama dan musuh alami, pengamatan ekosistem dan pengambilan keputusan pengendalian sendiri di lahannya secara periodik.

\section{Tujuan Kegiatan Pengabdian}

Pengabdian ini bertujuan untuk memberikan penyuluhan, pembimbingan, dan pendampingan kepada petani padi di Desa Pulau Rambai Kecamatan Kampa untuk menerapkan konsep pengendalian hama terpadu dalam pembudidayaan padi yaitu budidaya tanaman sehat, mengutamakan pengendalian alami menggunakan musuh alami, penggunaan pestisida alternatif terakhir, selain itu menyelamatkan dan meningkatkan kuantitas dan kualitas produksi padi sehingga pendapatan petani bertambah.

\section{Kajian literatur}

PHT merupakan konsep pengelolaan ekosistem pertanian yang berkelanjutan dan berwawasan lingkungan. Konsep PHT muncul sekitar tahun 1960-an dan di Indonesia memulai program PHT yang diawali dengan SL-PHT dimulai tahun 1989 setelah timbulnya dampak penggunaan pestisida sintetik untuk mengendalikan hama padi terhadap kesehatan masyarakat, lingkungan hidup, dan dapat mengurangi daya saing produk pertanian di pasar global. Oleh karenanya solusinya pendekatan dan teknologi pengendalian hama yang efektif dan ramah lingkungan, dimana tidak tergantung pada penggunaan pestisida sintetik yaitu penerapan teknologi PHT (Untung, 2008; Baehaki, 2015).

Food and Agriculture Organization (FAO) mendefinisikan PHT sebagai suatu pengelolaan hama yang dilakukan dalam konteks lingkungan terkait dan dinamika populasi spesies hama, memanfaatkan semua teknik dan metode pengendalian yang sesuai dan sekompetibel mungkin, serta mempertahankan populasi hama pada aras di bawah aras yang dapat mengakibatkan kerusakan atau kehilangan hasil yang secara ekonomi tidak dapat diterima (Food and Agriculture Organization, 2002).

Pengembangan dan penerapan PHT dalam pembudidayaan tanaman memperhitungkan ekosistem pertanian Indonesia yang khas. Dengan demikian perlu petani yang mandiri dan profesional dalam menerapkan prinsip PHT dalam pengelolaan ekosistem pertanian untuk kesejahteraan petani. Realisasi PHT tersebut dalam bentuk sistem pelatihan lapangan yaitu Sekolah Lapangan Pengendalian Hama Terpadu (SLPHT). SLPHT dalam bentukpendamping petani dan bimbingan satu musim tanam, petani dibimbing dalam melakukan pengelolaan tanaman, memantau hama, musuh alami, dan komponen ekosistem lainnya, membimbing dalam pengambilan keputusan pengendalian dengan menerapkan teknik-teknik pengendalian yang kompatibel dan ramah lingkungan. Tujuan akhir mendapatkan petani yang mandiri dapat menerapkan konsep PHT dalam budidaya dan menghasilkan petani yang ahli PHT yang dapat mengambil keputusan pengendalian yang tepat di lahannya sendiri (Untung, 2006; Baehaki, 2015).

PHT berlandaskan kepada ekologi sebagai konsep original untuk mengelola hama melalui studi interaksi hama dengan lingkungannya. PHT bio intensif menggabungkan faktor ekologi dan ekonomi sehingga dapat meningkatkan PHT yang berkelanjutan dengan mengurangi biaya untuk pemakaian pestisida dan mengurangi pencemaran lingkungan (Jepson, 2009).

Hasil penelitian (Settle et al., 1996) bahwa aplikasi insektisida pada permulaan musim tanam padi tidak hanya membunuh musuh alami hama padi, tetapi dapat membunuh serangga akuatik detrivora dan pemakan plankton yang hidup di air sawah. Keberadaan serangga air tersebut sangat bermanfaat karena menjaga populasi wereng coklat pada posisi yang tidak merugikan petani. Menghindarkan aplikasi insektisida pada permulaan musim tanam padi merupakan salah satu bentuk konservasi musuh alami yang efektif untuk pengendalian hama 
padi di Indonesia. Hasil penelitian (Herlinda dkk, 2008) bahwa keanekaragaman dan kelimpahan Arthropoda yang aktif di permukaan tanah tertinggi ditemukan pada sawah tanpa diaplikasikan insektisida sintetik yang terdiri dari 51 spesies (2503 individu) dan terendah pada sawah yang diaplikasikan insektisida sintetik yaitu 43 spesies (742 individu).

\section{METODE PENERAPAN}

Metode yang digunakan untuk mencapai tujuan pembinaan adalah melalui beberapa pendekatan yaitu:

1. Sebelum petani memulai penanaman padi dilakukan penyuluhan pengelolaan pembudidayaan tanaman padi dan pemaparan pengendalian hama padi yang alami ramah limgkungan. Dalam penyuluhan didiskusikan rencana penanaman yang akan dilakukan mulai dari bibit yang dipakai, jumlah bibit per rumpun, pengolahan tanah, pemberian kapur, pemupukan tanah dengan pupuk organik, cara-cara budidaya yang baik yang tidak mengundang serangan hama tinggi, pengenalan hama padi dan teknik pengendaliannya, pengenalan musuh alami, dan metoda monitoring atau pengamatan dan keputusan pengendalian hama.

2. Demontrasi tentang cara praktis dan alami mengendalikan hama menggunakan pestisida yangn alami seperti pestisida nabati dan agen hayati dalam bentuk insektisida mikroba kemasan serta pembuatan kompos.

3. Pendampingan dan bimbingan selama 1 musim tanam dalam pengamatan atau monitoring hama dan musuh alami, analisis ekosistem, pengambilan keputusan pengendalian hama yang diterapkan.

\section{HASIL DAN KETERCAPAIAN SASARAN}

\section{Alat Ukur Ketercapaian}

Alat ukur pencapaian tujuan pengabdian adalah

1. Pelaksanaan budidaya tanaman yang sehat yang tidak memicu serangan hama

2. Pengetahuan petani tentang jenis hama dan musuh alaminya serta pengendalian hama yang ramah lingkungan.

3. Perubahan pandangan petani tentang pengendalian hama tidak lagi mengutamakan pemakaian pestisida sintetik

4. Kemampuan petani melakukan pengamatan dan monitoring hama dan musuh alami di lahan tanaman padinya

5. Kemampuan petani sebagai ahli PHT yang dapat mengambil keputusan pengendalian hama di lahannya secara rutin dan berkala.

\section{Gambaran Umum Masyarakat Sasaran}

Masyarakat sasaran di desa Pulau Rambai, Koto Parambahan dan Desa Pulau Birandang umumnya pekerjaannya sebagai petani dengan persentase terbesar lulusan SD, tetapi distribusi secara keseluruhan terlihat tingkat pendidikannya sudah merata. Petani dalam menghadapi permasalahan hamapadi dibantu oleh PPL, dan umumnya solusi yang dianjurkan memakai pestisida sintetik. Konsep pengendalian hama secara terpadu yang dianjurkan untuk pengendalian hama padi tidak diketahui dan diterapkan petani dalam budidayanya dan pengendalian hamanya.

Hama yang sering menyerang tanaman padi dari komunikasi dengan petani adalah hama tikus, keong mas, walang sangit, wereng coklat, dan penyakit kresek. Serangan hama tersebut yang susah tidak bisa diatasi petani adalah hama tikus dan keong mas. Pengetahuan petani untuk mengendalikan hama tersebut masih sangat kurang, sehingga sering menurunkan produksi padi. Permasalahan hama tersebut juga timbul karena ketidaktahuan petani tentang faktor-faktor pemicu serangan hama tersebut di lahan. Di sekitar lahan yang ditanam petani banyak terdapat lahan yang tidak diolah sehingga tempat persembunyian tikus menjadi lebih banyak. Pengenalan tentang hama dan faktor-faktor yang mempengaruhi populasinya sangat 
perlu diketahui petani untuk dapat menerapkan budidaya tanaman yang sehat sesuai prinsip PHT.

Konsep pengendalian hama secara terpadu belum diterapkan petani padi, petani belum menerapkan teknik pengendalian yang ramah lingkungan, petani belum melalukan pengamatan atau monitoring hama rutin atau secara periodik sebelum melakukan keputusan pengendalian, petani belum begitu mengenal jenis musuh alami hama tanaman padi. Oleh karena itu penyuluhan untuk meningkatkan pengetahuan petani tentang hama padi dan penerapan pengendalian hama secara terpadu sangat diperlukan, sementara agar petani terbiasa melakukan pengamatan atau monitoring hama dan musuh alami sangat diperlukan pendampingan dan bimbingan secara rutin, sehingga diharapkan menjadi kebiasaan bagi petani, dengan demikian petani dapat menjadi ahli PHT di lahannya sendiri.

\section{Potensi Pengembangan (Pemberdayaan) Masyarakat}

Potensi yang ada baik sumberdaya alam dan masyarakat petaninya mendukung untuk diberdayakan. Keseharian masyarakat di Desa Pulau Rambai adalah bercocok tanam, bertani, buruh tani, berkebun karet dan kelapa sawit, beternak (sapi, kambing, ayam itik), perikanan, kontraktor, buruh bangunan serta berdagang dan lainnya. Mengingat keadaan wilayah di Desa Pulau Rambai adalah persawahan dan perkebunan $80 \%$ dari luas wilayah desa. Masyarakat umumnya sudah aktif mengolah lahan pertanian dengan menanam padi menggunakan cara yang sudah cukup baik.

Petani padi di Desa Pulai Rambai adalah masyarakat petani yang maju, berkeinginan besar untuk bertani, mau menerima masukan dari pemerintah melalui PPL, ini terlihat dari kegiatan bertani padi mengikuti yang telah diprogramkan, bantuan-bantuan yang diberikan pemerintah berupa pupuk organik, bibit padi, dan sebagainya disambut atau direspon positif oleh petani. Dengan demikian program yang dicanangkan dapat terlaksana dengan sosialisasi dari PPL. Komunikasi dan kegiatan sosialisasi berjalan baik.

\section{Solusi Pengembangan (Pemberdayaan) Masyarakat}

Potensi yang ada untuk pemberdayaan petani di Desa Pulau Rambai berpeluang besar dapat dilaksanakan program pengendalian hama padi secara terpadu, dengan solusi yang ditawarkan untuk pemberdayaan masyakarat petani padi adalah sebagai berikut:

1. Peningkatan pengetahuan petani padi dalam mengenal hama padi dan faktor-faktor budidaya yang mempengaruhi perkembangan hama sehingga antara teknik budidaya dapat disingkronkan dengan pengendalian hama.

2. Untuk itu perlu dilakukan penyuluhan tentang pengenalan dan pengendalian hama padi dan perencanaan pembudidayaan sebelum pembibitan dan penanaman sehingga tercapai budidaya tanaman yang sehat sesuai prinsip PHT dapat dilaksanakan

3. Perubahan cara pengendalian yang alami dan ramah lingkungansesuai konsep PHT maka penyuluhan adalah utama untuk pencapaian.

4. Agar pengamatan atau monitoring hama, musuh alami, dan ekosistem dapat terlaksana, maka pendampingan dan bimbingansecara periodik harus dilaksanakan sehingga petani sebagai ahli PHT dapat tercapai.

\section{Tingkat Ketercapaian Sasaran Program}

Pelaksanaan kegiatan desa binaan Pengendalian Hama Terpadu (PHT) pada tanaman padi di Desa Pulau Rambai pertama dilakukan konsolidasi dengan kepala desa dan aparatnya, konsolidasi dengan ketua kelompok tani, konsolidasi dengan petani percontohan, selanjutnya penyuluhan sebelum melakukan penanaman. Petani padi untuk lahan percontohan dilakukan cara budidaya yang telah dikonsep. Tanaman padi percontohanmelakukan budidaya tanaman yang sehat mulai dari persemaian, tanam sampai fase generatif, penerapan cara pembudidayaan yang telah diinformasikan pada saat penyuluhan.

Penyuluhan yang dilakukan di bulan Juni 2018 sebelum persemaian diselenggarakan di pondok sekitar hamparan lahan sawah petani. Media yang digunakan adalah papan tulis, spidol, spanduk dari karton yang berisi gambar jenis-jenis musuh alami, serta bahan-bahan pengendalian ramah lingkungan seperti tanaman sirih hutan, pestisida mikroba Thuricide dari 
Bacillus thuringiensis (Gambar 1). Untuk mengetahui tingkat ketercapaian program penyuluhan sebelum pelaksanaan penyuluhan disebarkan kuisioner yang harus diisi dulu oleh petani (Gambar 2). Saat pelaksanaan penyuluhan disebarkan pedoman jenis-jenis hama padi dan pengendaliannya secara terpadu. Materi penyuluhan yang diberikan adalah pemahaman konsep pengendalian hama terpadu, perencanaan budidaya mulai dari jenis varietas yang ditanam, cara persemaian, cara penanaman, pengenalan hama dan musuh alaminya, pengendalian dan faktor-faktor budidaya pemicu serangan hama padi. Pengendalian yang ditekankan dalam penyuluhan adalahteknik pengendalian yang ramah lingkungan yaitu menggunakan pestisida nabati, agen hayati, terutama pengenalan musuh alami hama tanaman padi sesuai konsep PHT.

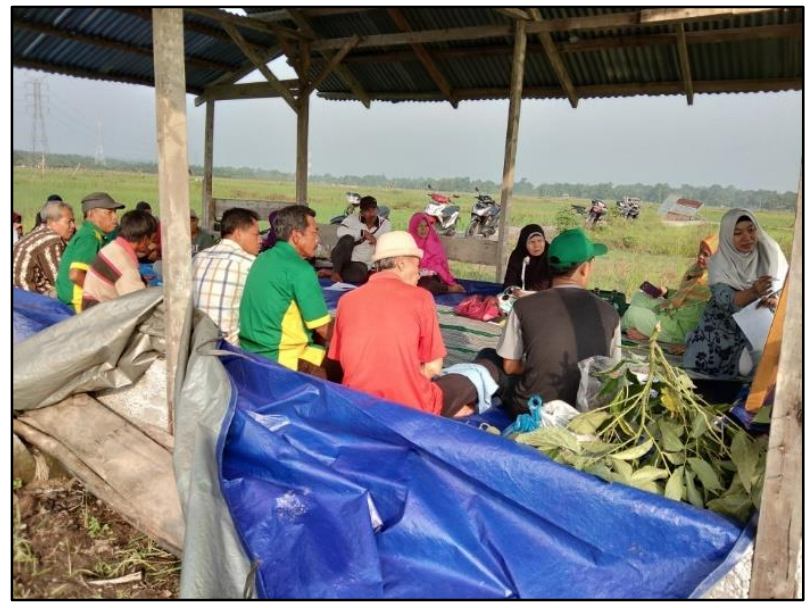

Gambar 1. Penyuluhan dan demonstrasi pengenalan dan pembuatan pestisida nabati
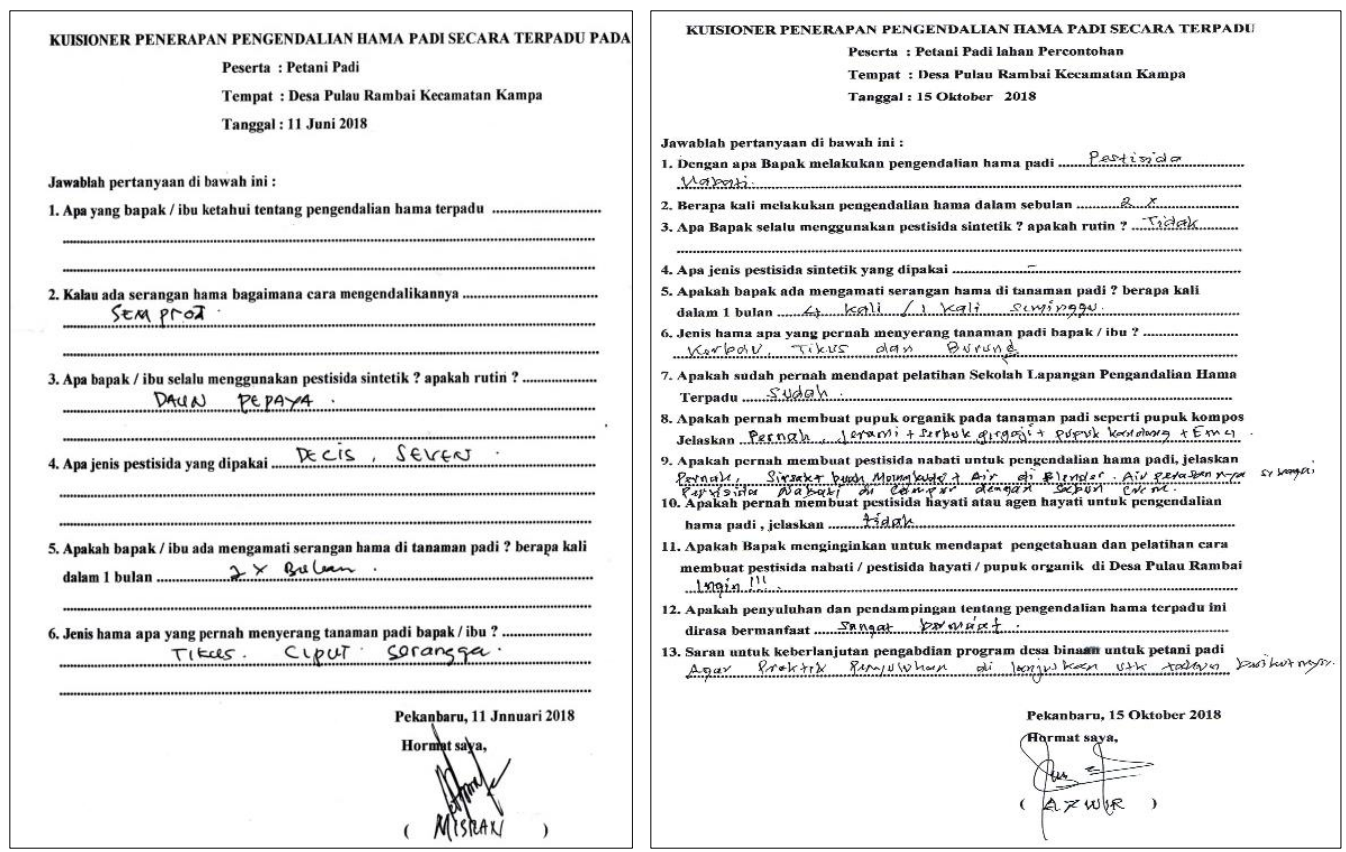

Gambar 2. Kuisioner diisi petani sebelum kegiatan penyuluhan dan diakhir kegiatan

Pemaparan jenis-jenis hama dan pengendaliannya dengan cara penjelasan, demostrasi dan diskusi. Jenis musuh alami hama dikenalkan dalam bentuk spanduk dari karton diisi gambargambar musuh alami hama padi tani yang dijelaskan satu persatu hama yang dimangsa, diparasiti dan diinfeksinya (Gambar 3). Satu jenis hama dijelaskan, cara pengelolaan hama yang dapat mengurangi perkembangannya dalam pembudidayaan padi, langsung diberi kesempatan kepada petani untuk mengajukan pertanyaan, ditunjukkan musuh alami yang 
dapat membunuh hama tersebut. Selanjutnya, masuk ke jenis hama berikutnya dijelaskan lagi, kemudian tanya jawab, dan begitulah seterusnya.

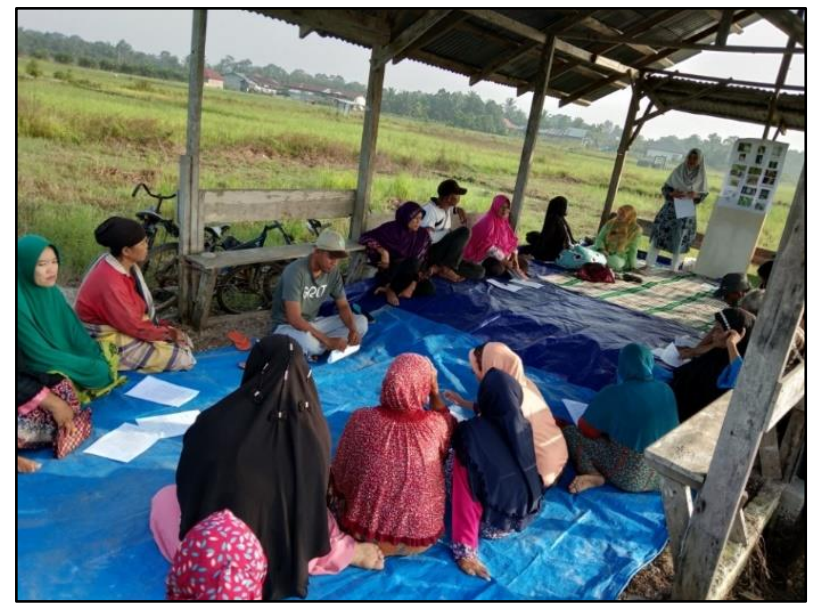

Fauzana dkk.

Gambar 3. Penyuluhan dilaksanakannya di pondok sekitar hamparan sawah petani

Petani padi peserta penyuluhan sangat memperhatikan, antusias dan sangat respon terhadap penyuluhan yang diberikan, walaupun dilaksanakan pada jam 8 pagi saat bulan puasa, tetapi petani tetap semangat sampai akhir penyuluhan. Materi pengendalian hama secara terpadu pengendaliannya tidak semudah pengendalian dengan pestisida sintetik, sehingga ada petani yang komentar kalau hamanya wereng coklat obatnya apa atau pestisida sintetik yang dipakai. Jadi penerapan pengendalian hama terpadu bagi petani memerlukan pemahaman untuk dapat dilaksanakan. Oleh karena itu disamping penyuluhan diperlukan pendampingan dan bimbingan agar tujuan pengabdian tercapai, petani dapat melaksanakan pengamatan hama secara berkala sepanjang budidaya tanaman padi, sehingga serangan hama dapat dideteksi sedini mungkin.

Prinsip PHT adalah budidaya tanaman yang sehat, tanaman yang sehat akan kuat dari serangan hama, maka perlu perencanaan penanaman agar teknik budidaya tanaman yang dilakukan tidak sesuai untuk perkembangan hama. Untuk itu dibuat tanaman percontohan, teknik budidaya yang disarankan untuk lahan padi yaitu pemeriksaan $\mathrm{pH}$ tanah, hasil analisis didapat tanah $\mathrm{pH} 5$, maka dianjurkan melakukan pengapuran. Pupuk yang digunakan dianjurkan pencampuran pupuk sintetik pupuk kandang, dan pupuk organik,varietas padi digunakan batang piaman, cara penanaman sistem legowo 4:1, dengan 3 bibit per rumpun (Gambar 4 dan Gambar 5). Dengan demikian cahaya dapat masuk dari segala arah dan kelembaban tanaman tidak terlalu tinggi, sehingga tidak bagus untuk perkembangan hama.

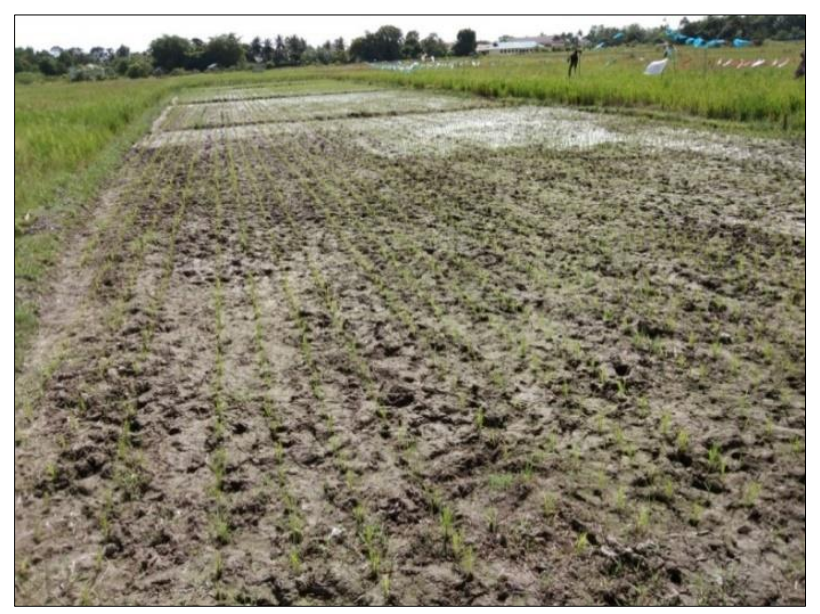

Gambar 4. Tanaman padi percontohan umur 1 bulan 

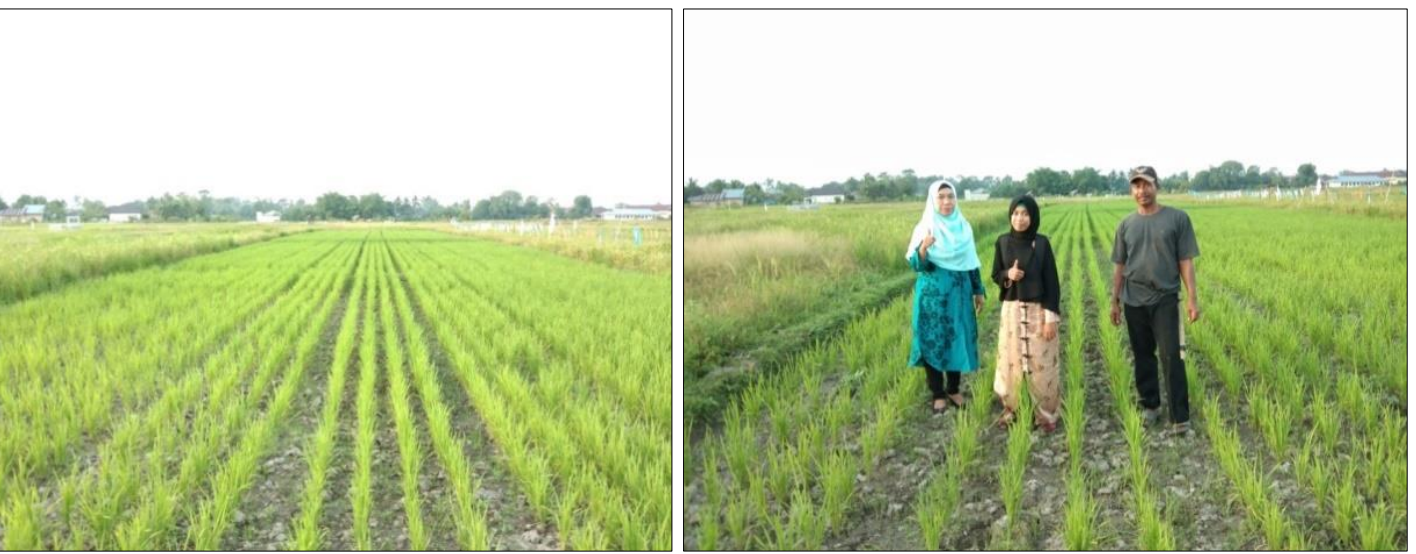

Gambar 5. Tanaman padi percontohan umur 2 bulan

Pupuk organik yang diaplikasikan petani pada tanaman percontohan didapat dari Dinas Pertanian dan ditambah pupuk kompos yang disarankan untuk dibuat sendiri oleh petani dari jerami padi dari penanaman sebelumnya dipotong-potong, dibuat lubang dekat sawah, dibenamkan ke tanah dengan menambah pupuk kandang dan EM 4, selanjutnya diinkubasi selama 1 bulan.

Pengendalian hama yang disarankan selama pendampingan tanaman percontohan hanya menggunakan pestisida nabati dan agen hayati, tidak dibolehkan menggunakan pestisida sintetik. Petani menggunakan pestisida nabati dari tanaman sirsak untuk pengendalian hama. Pembuatan insektisida nabati dari daun sirsak dijelaskan saat datang 1 kali sebulan secara komunikasi langsung. Penjelasan pembuatan secara informal yang mudah dilakukan petani dengan penumbukan daun, perbandingan air dan bahan 1:10, dilakukan pengadukan, penyaringan dan penambahan sabun krim $1 \mathrm{~g}$. Aplikasi dilakukan petani percontohan 1 sampai 2 minggu sekali.

Pestisida hayati diberikan ke petani percontohan dalam bentuk insektisida mikroba kemasan produk BT Plus dari bakteri entomopatogen Bacillus thuringiensis, dan BVR dari jamur Beauveria bassiana. Pemakaian oleh petani bergantian dengan pestisida nabati daun sirsak.

Hasil pengamatan atau monitoring terhadap hama dan musuh alami di tanaman padi percontohan, hama populasi rendah, sementara musuh alami banyak ditemukan di tanaman sampel yang diamati. Satu rumpun tanaman padi rata-rata ditemukan 3-5 musuh alami. Jenis musuh alami yang ada terlihat berbagai macam yaitu jenis predator Paederus fuscipes, Ophionea sp., Micraspis sp., Conocephalus longipennis, Lycosa pseudoannulata, dan jenis parasitoid Trichogramma sp., dan lainnya.

Padi fase generatif sudah terbentuk gabah untuk mengatasi serangan hama walang sangit petani disarankan memakai jala agar hama walang sangit tidak dapat mengisap gabah padi. Jala disediakan untuk tanaman percontohan, petani memasangnya pada awal fase generatif.

\section{KESIMPULAN}

Pengendalian hama secara terpadu pada tanaman padi diterapkan petani di Desa Pulau Rambai dapat mengurangi populasi hama padi, meningkatkan musuh alami pada rumpun tanaman padi, meningkatkan pertumbuhan tanaman dan produksi padi yang lebih baik.

Pembinaan petani di Desa Pulau Rambai agar memberi hasil yang maksimal dalam pengendalian hama ramah lingkungan sesuai konsep PHT, sangat diperlukan keberlanjutan agar petani mendapat keahlian, keterampilan dalam membuat, memproduksi pestisida hayati dan pupuk organik sendiri.

\section{UCAPAN TERIMA KASIH}

Penulis mengucapkan terima kasih kepada Lembaga Penelitian dan Pengabdian kepada Masyarakat Universitas Riau skema Desa Binaan tahun 2018 di bawah DIPA Universitas Riau 
dengan nomor kontrak 1353/UN.19.5.1.3/PP/2018 yang telah memberikan dana untuk pelaksanaan kegiatan desa binaan di Desa Pulau Rambai Kecamatan Kampa Kabupaten Kampar.

\section{Daftar Pustaka}

1. Baehaki. 2015. Strategi Pengelolaan Serangga Hama di Lahan Pertanian untuk Menunjang Tercapainya Ketahanan Pangan di Indonesia. Dalam Seminar Nasional dan Musyawarah Anggota Perhimpunan Entomologi Indonesia (PEI) Cabang Bandung, Bandung, 15 Oktober 2015.

2. BPS Kabupaten Kampar. 2018. Kabupaten Kampar Negeri Serambi Mekah. http://kamparkab.go.id/home/page/luas-wilayah-kecamatan Diakses 10 Januari 2018.

3. Brittain, C., R. Bommarco, M. Vighi, S. Barmaz, J. Settele, and S.G. Potts. 2010. The Impact of an Insecticide on Insect Flower Visitation and Pollination in an Agricultural Land-scape. Agricultural and Forest Entomology 12: 259-266. https://doi.org/10.1111/j.14619563.2010.00485.x

4. Food and Agriculture Organization. 2002. International Code of Conduct on the Distribution and use of Pesticides (Amended version). Rome: Food and Agriculture Organization.

5. Herlinda, S., Waluyo, S.P. Estuningsih, dan C. Irsan. 2008. Perbandingan Keanekaragaman Spesies dan Kelimpahan Arthropoda Predator Penghuni Tanah di Sawah Lebak yang Diaplikasi dan Tanpa Aplikasi Insektisida. Jurnal Entomologi Indonesia 5(2): 96-107. http://journal.ipb.ac.id/index.php/entomologi/article/view/6030

6. Jepson, P. 2009. Biointensive Integrated Pest Management (IPM). IPPC. 2040 Cordley Hall, Oregon State University, Corvallis, OR 97331. 8p.

7. Matsumura, M., and S. Sanada-Morimura. 2010. Recent Status of Insecticide Resistance in Asian Rice Planthoppers. Japan Agricultural Research Quarterly 44: 225-230. https://doi.org/10.6090/jarq.44.225

8. Settle, W.H., H. Ariawan, E.T. Astuti, W. Cahyana, A.L. Hakim, D. Hindayana, A.S. Lestari, Pajarningsih, and Sartanto. 1996. Managing Tropical Rice Pests Through Conservation of Generalist National Enemies and Alternative Prey. Ecology 77(7): 1975-1988. https://doi.org/10.2307/2265694

9. Untung, K. 2006. Pengantar Pengelolaan Hama Terpadu. Yogyakarta: Gadjah Mada University Press.

10. Untung, K. 2008. Pengelolaan Hama Terpadu Model Pertanian Berkelanjutan. Kumpulan Makalah. Yogyakarta: Fakultas Pertanian UGM.

11. Wanger, T.C., A. Rauf, and S. Schwarze. 2010. Pesticides and Tropical Biodiversity. Frontiers in Ecology and the Environment 8: 178-179. https://doi.org/10.1890/10.WB.015 